\title{
RETRATOS DA ESCRITA: ESPAÇOS DE ENUNCIAÇÃO, MEMÓRIA E LÍNGUA DE IMIGRAÇÃO.
}

\author{
REJANE FIEPKE CARPENEDO (UFSM)
}

\begin{abstract}
RESUMO: O presente artigo apresenta os primeiros movimentos teórico-metodológicos de nossa pesquisa de doutorado, ainda em fase inicial de desenvolvimento. Os estudos já existentes relacionados às línguas de imigração, em sua maioria são voltados ao período da interdição linguística durante o Estado Novo, estudos fonéticos e fonológicos, ou na área da análise de discurso. Assim, propomo-nos a pensar a língua de imigração alemã na perspectiva da Semântica do Acontecimento (Guimarães, 2002), e a partir disso pesquisar em que espaços de enunciação, públicos e privados, circula a língua de imigração alemã escrita, e quais os sentidos políticos e memórias da língua que circunscrevem esses espaços. O estudo se dá no município de Novo Machado, na região noroeste do Rio Grande do Sul, colonizado predominantemente por imigrantes alemães e italianos. O processo metodológico adota fotografias como materialidade de registro do corpus, para investigar quais os espaços de enunciação em que a língua de imigração alemã se inscreve atualmente. Até este momento da pesquisa, observam-se registros de língua escrita em lápides de cemitérios (espaço público), e, por meio de um movimento analítico inicial observam-se os sentidos políticos que circunscrevem esse espaço de enunciação.
\end{abstract}

PALAVRAS-CHAVE: Língua de Imigração Alemã. Espaço de Enunciação. Memória da Língua. Enunciação.

ABSTRACT: This article presents the first theoretical-methodological movements of our doctoral research, still in the initial phase of development. Existing studies related to immigration languages are mostly focused on the period of linguistic interdiction during Estado Novo, phonetic and phonological studies or in the area of discourse analysis. Thus, we propose to think the German immigration language in the perspective of the Semantics of the Event (Guimarães, 2002), and from this to investigate in which spaces of enunciation, public and private, circulates the written German immigration language, and which political senses and memories of the language that circumscribe these spaces. The study is conducted in the municipality of Novo Machado, in the northwestern region of Rio Grande do Sul, colonized predominantly by German and Italian immigrants. The methodological process adopts photographs as corpus registration materiality, to investigate the spaces of enunciation in which the German immigration language is currently inscribed. Until this moment of the research, we observed written language records on tombstones of cemeteries (public space), books and letters (private spaces).

KEYWORDS: Language of German Immigration. Enunciation space. Memory of Language. Enunciation.

\section{PERSPECTIVA DA PESQUISA}

A realização desta pesquisa se justifica cientificamente por se apresentar como um estudo inédito no campo enunciativo, por mobilizar fotografias da escrita da língua como materialidade enunciativa para objeto de análise, e ser uma investigação sobre o status atual da língua de imigração alemã escrita no município de Novo Machado - RS. Também, nos 


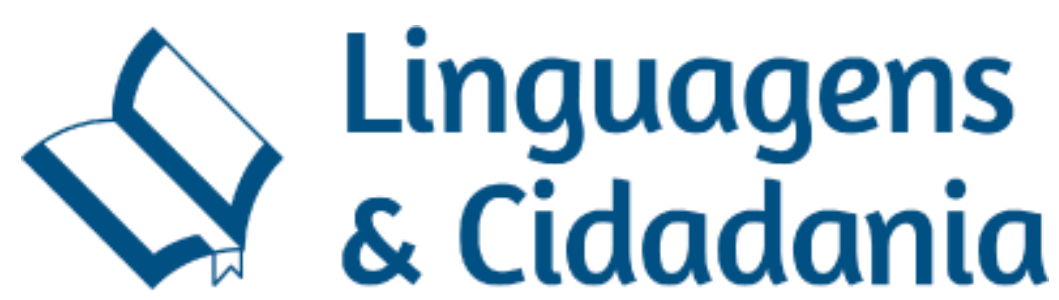

propomos a pensar metodologicamente a construção do corpus, e para tal, se fará necessário criar um critério de ordenação do arquivo de fotografias.

Ainda, esta proposta se vincula a nossa pesquisa de mestrado, desenvolvida a partir da temática "A língua no discurso do senso comum: ideologia e imaginário", em que os resultados apontam para a existência de um imaginário fortemente marcado no senso comum de que o Brasil é um país de homogeneidade linguística. Ao encontro disso, a pesquisa a ser desenvolvida no doutorado se propõe a apresentar um estudo a partir de uma, das tantas, línguas de imigração que ainda coexistem com a língua portuguesa em solo nacional, refutando a ideia de que "todos falam a mesma língua e da mesma forma".

As línguas de imigração e políticas linguísticas têm sido objeto de diferentes estudos no campo da linguística. A citar alguns trabalhos mais conhecidos, temos Maria Onice Payer (2009) e Carmen Zink Bolognini (2005), voltando-se à memória da língua de imigração italiana e à nacionalidade; Vejane Gaelzer (2014), que reflete acerca das relações entre identidade, memória e história a partir de construções imaginárias e discursivas de sujeitos descendentes de imigrantes alemães; trabalhos estes pensados na perspectiva da Análise de Discurso Francesa. Há também pesquisas desenvolvidas no Programa de Pós-Graduação em Letras da UFSM, a citar Juciane Ferigolo Parcianello (2011), que em sua dissertação de mestrado abordou a memória discursiva e as fronteiras enunciativas a partir de entrevistas com sujeitos descendentes de imigrantes italianos na região da Quarta Colônia; Viviane Brust (2013), que pensa a memória da imigração italiana na Quarta Colônia a partir de outra materialidade, os monumentos ao imigrante.

Nesse sentido, nosso objetivo é pensar como a língua de imigração circula hoje, em quais os espaços ela está destinada a ser usada em sua forma escrita, e como se dá a disputa com a língua portuguesa. Lembrando que essa disputa é política, em que os sujeitos por meio de uma decisão politicamente realizada optam por qual língua irá ocupar esses espaços.

Dessa forma, é imprescindível considerar o político no espaço enunciativo, pois o ato de enunciar está inserido em um espaço sócio histórico, o que por sua vez, irá determinar as ações dos sujeitos, inclusive da fala. Mariani (2004, p. 40), explica as escolhas do sujeito no ato de sua manifestação pela linguagem, afirmando que "usar uma palavra é não usar outra, é fazer recortes em regiões de sentidos sem ter nenhuma garantia de um entendimento 


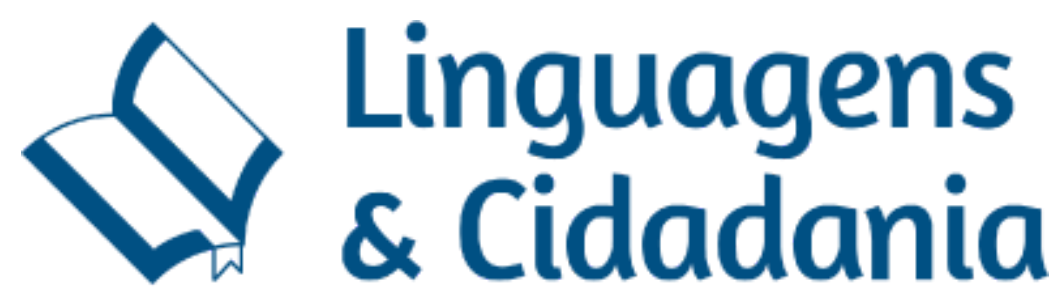

absoluto, é inscrever-se em redes de filiações de sentidos, as memórias e esquecimentos constitutivos do dizer.”. Tamanha é a decisão política, então, de escolher a língua alemã para o epitáfio da lápide, simbolicamente significado como as últimas palavras dos sujeitos, e que pela inscrição na pedra, permanecem, resistindo ao tempo.

Em uma reflexão inicial, somos incitadas a pensar também em uma relação de pertencimento identitário que passa pela língua. Nessa perspectiva, observa-se um pertencimento ao lugar e um pertencimento à língua, e há diferença entre estes, pois em uma lápide com inscrições em alemão em um cemitério no Brasil, há um lugar de memória que se dá pela língua, ou seja, há pertença à língua materna, mas não necessariamente ao lugar. Gaelzer (2011, p.150), em seus estudos discursivos acerca dos imigrantes alemães, afirma que "É pela preservação da língua que se cultivam as memórias, a cultura e o sentimento de pertencimento de um povo.”.

Assim, quando hoje se aproximam os 200 anos da imigração alemã no Brasil e os 80 anos da interdição linguística promovida pelo projeto de Nacionalização da Era Vargas por meio do Decreto-Lei $n^{\circ}$ 406, de 04 de Maio de 1938, somos instigados a lançar um olhar sobre uma língua de imigração que sobrevive aos efeitos do tempo, das políticas linguísticas, e da ideologia linguística de um país que crê ser monolíngue. A materialidade enunciativa que mobilizamos, a escrita, que foi amplamente difundida pela religião e pela escola, consiste hoje apenas em memória, ou há quem siga escrevendo a língua? Em que espaços de enunciação estão as memórias da língua, e em que espaços a língua ainda é escrita?

Ressaltamos que há uma dupla importância nesta proposta: a já referida, de contribuir para o saber científico sobre a língua de imigração alemã, e de apresentar ao município de Novo Machado um estudo do cenário da língua alemã escrita, língua que representa uma parcela significativa dos sujeitos do lugar.

\section{PERCURSO TEÓRICO-METODOLÓGICO: MOVIMENTOS INICIAIS}

Buscamos agora nos acercar de contribuições conceituais e teóricas pertinentes para a pesquisa, por meio de uma breve reflexão dos conceitos adotados, no intuito de ampliar a compreensão dos arranjos teóricos suscitados pelos objetivos deste estudo. Conforme Benveniste (2006, p.29), a Linguística é uma ciência que visa a "transformar as palavras que 


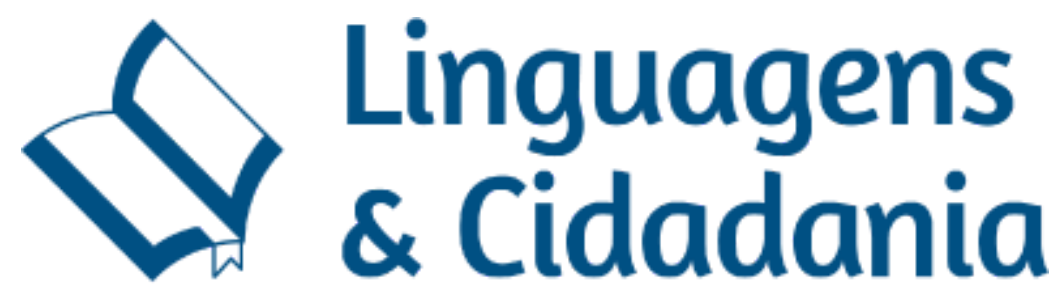

voam em uma matéria concreta, que se estuda, que se disseca, onde se delimitam unidades, onde se isolam níveis". Isso se denomina teoria. Em outras palavras, o mecanismo que permite a concretude e análise de certa matéria. E nesta pesquisa, pretendemos desenvolver uma reflexão a partir da ferramenta teórica e analítica da Semântica do Acontecimento, com foco no conceito de Espaço de Enunciação, pensado por Guimarães (2005), no campo da Teoria da Enunciação. Bem como, é imprescindível que se reflita também acerca do político na enunciação, da memória na língua, e do funcionamento das políticas linguísticas.

Guimarães (2005, p.7) afirma que a Semântica do Acontecimento "constitui uma semântica que considera que a análise do sentido da linguagem se deve localizar no estudo da enunciação, do acontecimento do dizer”. Assim, temos uma semântica linguística com foco na observação do sentido presente no enunciado, pois para o autor, o sentido não é apenas uma relação entre a expressão e o real, e sim, são as relações das formas que significam no enunciado. Deste modo, somente podemos compreender o significado de uma forma quando consideramos o seu funcionamento como inerente ao sentido do enunciado.

\begin{abstract}
Saber o que significa uma forma é dizer como seu funcionamento é parte da constituição do sentido do enunciado. Mas para mim, considerar o processo no qual uma forma constitui o sentido de um enunciado é considerar em que medida esta forma funciona num enunciado, enquanto enunciado de um texto. Ou seja, não há como considerar que uma forma funciona em um enunciado, sem considerar que ela funciona num texto, e em que medida ela é constitutiva do sentido do texto (GUIMARÃES, 2005, p.7).
\end{abstract}

Compreendemos assim, que não é possível tomar os enunciados isolados de seus textos para estudar os sentidos, uma vez que "A enunciação é tomada como um acontecimento histórico, ou seja, não no sentido da história cronológica, onde os fatos significam um acontecimento social determinado apenas no tempo, sendo, desse modo, um fato sempre único e irrepetível." (Guimarães, 2002, p.17). Do contrário, é compreendida em um sentido em que a história é constitutiva do presente de uma enunciação, e com isso a sua significação é determinada pelas condições sociais de existência. Por isso, a temporalidade é constituída no acontecimento da enunciação.

Partindo dessa particularidade do acontecimento enunciativo, e do seu funcionamento na linguagem, Tatsch (2013), explica como os sentidos são produzidos no entorno do acontecimento enunciativo. 
A língua está em constante movimento nesse espaço enunciativo, constituindo, mantendo e atualizando sentidos. Por isso o acontecimento faz surgir o novo, produzindo sentidos pelo funcionamento da língua. Funcionamento esse orientado por uma memória de dizeres sociais, a partir dos quais a língua passa a significar. Nessa perspectiva, o acontecimento enunciativo é permeado por determinações de sentido. (TATSCH, 2013, p. 211).

Guimarães (2005), afirma que para que se tenha um acontecimento é preciso destacar dois elementos que são imprescindíveis para sua realização: a língua e o sujeito na constituição histórica do sentido. Além desses elementos, podemos considerar também que a temporalidade dos acontecimentos é um fator relevante para definir o sentido das formas e expressões e sugerir novos gestos de leitura e novas interpretações. Ressaltando que para que tenhamos um funcionamento discursivo, é fundamental que haja uma materialidade histórica do real, levando em consideração o sujeito físico, que produz as enunciações, bem como, um sujeito, neste caso, o sujeito imigrante ou descendente de imigrantes alemães, que enuncia "[...] afetado pelo simbólico e num mundo vivido através do simbólico.”.

Esses aspectos do acontecimento enunciativo implicam o funcionamento de uma memória da língua, que para Guimarães $(1996$, p.27) “[...] é uma memória latente, pois para significar precisa confrontar-se sempre com a memória discursiva e o presente do acontecimento. E assim, por ser latente, pode sempre ser outra coisa, para isso bastando que outras enunciações a façam derivar, mesmo que imperceptivelmente". Nesse sentido, temos o funcionamento da língua de imigração alemã a partir dos movimentos do interdiscurso, e da memória do dizer, ou seja, quando está exposta ao interdiscurso a língua está concomitantemente exposta a uma memória dizível.

Payer (2006) afirma que inerente ao funcionamento da memória da língua, há um funcionamento político, pois a linguagem carrega memórias de sentidos que constituem o modo de significar do sujeito, sobretudo em seu enunciar.

Memórias múltiplas, inscritas em elementos diversos da linguagem, manifestam-se facilmente em situações que se apresentam conflituosas. Este é o caso, quando as línguas junto às memórias que elas trazem, se colocam em contato, entrando em confronto, em diversos contextos específicos de conformidade com as formações sócio-históricas. (PAYER, 2006, p.12). 


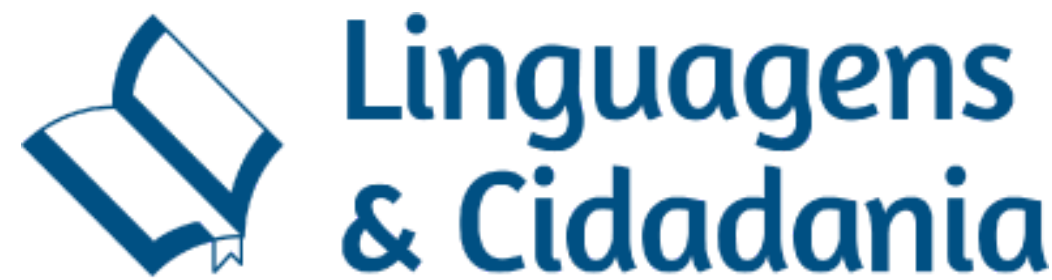

Em síntese, o sentido é produzido pela enunciação, o que significa dizer que se constitui no e pelo acontecimento do funcionamento da língua. Para Guimarães (2018, p.22) "este acontecimento se apresenta como se dando pela existência de uma língua, porque há falantes que são tomados enquanto falantes pela relação com tal língua”. Destacando que para o autor, o falante não consiste em uma pessoa física, mas “[...] é um lugar de enunciação determinado pela relação com a língua, no que chamamos espaço de enunciação.”. Isso significa que não há línguas sem outras línguas, na mesma proporção em que não há línguas sem falantes, e vice-versa.

Um detalhe fundamental na configuração do espaço de enunciação é que as línguas do espaço de enunciação são distribuídas de modo desigual, pois conforme Guimarães (2018, p.24) “[...] não se é falante das línguas deste espaço da mesma maneira. O espaço de enunciação é, então, um espaço político do funcionamento das línguas.”.

Dessa forma, percebemos que o político e a enunciação são constitutivos, pois ao enunciar, o sujeito significa, e com isso, se inscreve na história. A Semântica do Acontecimento, teoria adotada nesta pesquisa, se filia ao materialismo histórico, e assim dialoga com o funcionamento do político na linguagem. Weber $(2013$, p.18) destaca que "para que o político se constitua na língua é preciso haver enunciação".

Quando se fala no lugar do político na linguagem se está afirmando a sua constituição por meio das condições sócio-históricas, e concomitantemente, se assume que a língua está afetada pelas relações sociais. Conforme Orlandi (2002), o político é da ordem do conflito, da diferença, do dissenso, se destacando pela disputa “dos princípios que regem a vida social em suas diferenças, sendo ele próprio a prática dessas diferenças”.

Para Guimarães (2002, p. 16), o político na língua é incontrolável, pois “[...] é caracterizado pela contradição de uma normatividade que estabelece (desigualmente) uma divisão do real e a afirmação de pertencimento dos que não estão incluídos.”. Assim, o político enquanto diferença de sentidos “[...] é próprio da divisão que afeta materialmente a linguagem.”. Com isso, os espaços de enunciação da língua de imigração alemã em sua forma escrita são espaços atravessados pelo funcionamento político, uma vez que significa uma escolha do sujeito ao inscrever o seu pertencimento a uma língua em determinado lugar. 
Orlandi (2013) explica a relação da língua com suas respectivas políticas, classificando-as conforme as suas razões.

Falar é uma prática política no sentido amplo, quando se consideram as relações históricas e sociais do poder sempre inscritas na linguagem. Paralelamente a esta forma geral de presença do político na linguagem, nós podemos considerar uma noção mais restrita, mais técnica: é a política das línguas ou a política linguística. Pensamos a política linguística a partir de três posições distintas:

1. As políticas linguísticas como razões do Estado, das Instituições que apresentam a questão da unidade como valor (como princípio ético);

2. As políticas linguísticas como razões que regem as relações entre povos, entre nações, Estados: a questão da dominação como valor (como princípio ético);

3. As políticas linguísticas como razões relativas aos que falam as línguas: a questão da diversidade como valor (como princípio ético). (ORLANDI, E, 2013, p.106)

Com isso, compreendemos que os espaços de enunciação de funcionamento da língua de imigração alemã escrita são atravessados por uma política linguística que configura esse funcionamento. Nesses espaços, ocorre uma disputa de sentidos, significada não necessariamente por uma política linguística de Estado, mas inerente às razões das escolhas linguísticas dos sujeitos.

Em um espaço político em que o conflito entre as línguas é constante, a língua de imigração sobrevive. E, nesse sentido, Brust (2013, p. 56) propõe a língua de areia, como sendo "aquela pela qual a memória da imigração permanece, ainda que fragmentada e dispersa.”. E desses fragmentos dispersos de língua escrita, constituiremos o nosso corpus.

O percurso metodológico inicia a partir da nossa materialidade enunciativa, a fotografia, que é pensada enquanto instrumento que constituirá um arquivo a ser analisado. Ou seja, a fotografia é o instrumento adotado para o registro dessa materialidade enunciativa, a língua escrita nos espaços de enunciação públicos e privados. Assim, por meio do estudo da literatura já existente em relação à temática, mobilizamos o arcabouço teórico-metodológico da Semântica do Acontecimento, pensado por Guimarães (2002) na perspectiva da Teoria da Enunciação. Dessa forma, nos valemos dos conceitos tanto para a questão teórica, especialmente o Espaço de Enunciação, como para os procedimentos metodológicos de análise. 
anteriormente,

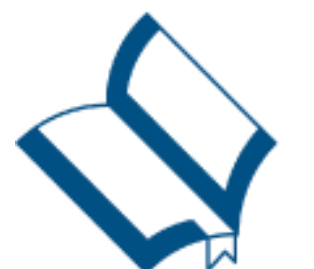

Como

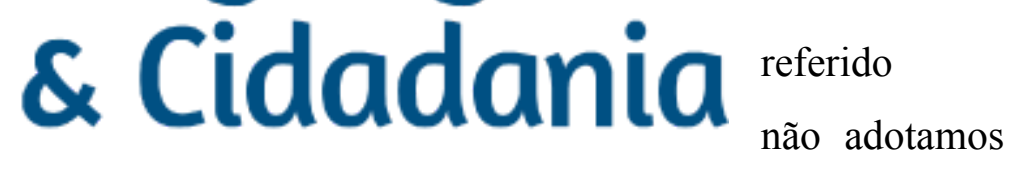

um corpus pronto, mas nos desafiamos a construí-lo por meio de fotografias da escrita. Para tal, é parte da pesquisa pensar metodologicamente em como estabelecer critérios para a construção e ordenação dessas

fotografias dos espaços de enunciação da língua de imigração alemã escrita. Nesse sentido, acreditamos ser pertinente pensar a noção de arquivo enquanto método de organização do saber.

Os espaços de enunciação serão buscados por meio de informações prévias que já possuímos, como por exemplo, de que há língua alemã escrita em locais públicos como cemitérios, documentos de igrejas e museu municipal. E, em sequência, adotaremos o método de pesquisa em comunicação Bola de Neve, que, conforme Baldin e Munhoz (2011), consiste na identificação e recrutamento de atores sociais reconhecidos por seus pares em decorrência de seu papel de liderança na comunidade estudada. A estes, acrescentaremos informantes por meio de indicações de moradores locais, até que em um dado momento o conjunto de informações/indicações de lugares começa a se repetir. É nossa pretensão buscar espaços de enunciação públicos e privados em todas as localidades do município colonizadas por imigrantes alemães e seus descendentes, e para conhecer esses lugares recorremos às historiadoras locais Priebe e Schroeder (2005).

Para pensar a fotografia como objeto que irá constituir o nosso corpus enquanto materialidade de registro dos enunciados, nos apoiamos em Brust (2013), que em sua dissertação de mestrado pensa a constituição do documento fotográfico a partir das definições de fotografia e documento. Em um movimento inicial, o documento fotográfico é uma perspectiva para se pensar os espaços de enunciação e a memória da língua, pois de acordo com Brust (2013, p.79) “[...] se fotografia é o registro de uma imagem, o documento fotográfico a que nos referimos é o que atesta, pela fixação de uma imagem, a existência de algo [...]", no caso, os espaços de enunciação em que circula a língua de imigração alemã em sua forma escrita. Assim, o conceito de documento fotográfico funciona em virtude de que as fotografias serão de enunciados de língua escrita, ou seja, de certo modo se constituem como memória documental de uma língua. 
Em

processo de

fotografias, nos resta pensar metodologicamente a ordenação dessa materialidade, para então proceder com o movimento analítico dos espaços de enunciação mobilizados. Ao adotar os procedimentos metodológicos referidos, acreditamos ser possível responder à questão cerne que move esta pesquisa.

Em decorrência dos vastos estudos sobre a imigração alemã no Brasil, que abrangem principalmente os contatos linguísticos e o período da interdição das línguas durante a Era Vargas, nos desafiamos a investigar os espaços, públicos e privados, em que há enunciados em língua alemã escrita. Por meio de fotografias desses locais/objetos, que, segundo a compreensão de Brust (2013), podem ser referidas como documentos fotográficos, procederemos com a análise do corpus construído. Para situar a pesquisa no espaço sócio histórico, destacamos que as fotografias serão realizadas no município de Novo Machado, na região noroeste do Estado do Rio Grande do Sul, em virtude do fato de ser um município colonizado inicialmente por imigrantes alemães que junto aos seus descendentes prezavam muito pela manutenção da língua, conforme as historiadoras locais Priebe e Schroeder (2005) destacam:

\footnotetext{
Os imigrantes alemães, talvez mais do que as outras etnias, mantiveram muito fortes as suas tradições e a sua cultura, especialmente, através do cultivo da língua, na própria família, nas práticas religiosas e, da mesma forma, na educação escolar, pois os próprios alemães organizaram suas escolas, administrando-as. (PRIEBE e SCHROEDER, 2005, p. 59).
}

Assim, compreendemos que os espaços em que circula a língua se constituem como coletivos, religião, comunidade e escola, e privados, no âmbito familiar. Nesse sentido, entendemos também que há políticas linguísticas que circunscrevem esses espaços de enunciação, pois ao determinar quais os espaços que a língua de imigração alemã escrita irá ocupar, seja por meio de objetos e documentos antigos guardados, ou por registros atuais, há um funcionamento político implicado.

Vale destacar que para esta pesquisa adotamos o conceito de língua referido por Guimarães (2018, p.23), em que “[...] a língua não é algo abstrato, é algo histórico, se 
apresenta pela

humana, por

fundamentam o funcionamento desta prática cuja característica é a de produzir significações".

A partir de um movimento de pesquisa inicial, por meio da busca de espaços em que a língua de imigração alemã se inscreve, encontramos inúmeras lápides situadas no cemitério municipal de Novo Machado que possuem as suas inscrições em alemão.

\section{DA VIDA PARA A LÁPIDE: SILENCIAMENTO E RESISTÊNCIA}

A história da imigração implica a relação sujeito e língua, dada a imposição e o apagamento de línguas. Percebemos ainda que a sensibilidade presente nessa delicada relação com as línguas e as formas linguísticas é o que constitui o sentido. Assim, consideramos possível estabelecer um estatuto mais consistente à presença de um vasto material "silenciado" ao longo da história brasileira, que sobrevive, permanece, como memória de línguas apagadas, produzindo, desse modo, os seus efeitos de sentido nos enunciados.

A partir disso, sustentamos a nossa reflexão acerca do espaço de enunciação em que localizamos as primeiras inscrições em língua alemã nos enunciados das lápides de imigrantes alemães e seus descendentes, no cemitério do município de Novo Machado - RS. Nesse sentido optamos por lançar um olhar para os epitáfios nas lápides de imigrantes alemães e seus descendentes, como últimas palavras do sujeito, palavras que permanecem, se eternizam com o tempo, se transformam em memória e posteriormente em patrimônio. As imagens consistem em registros fotográficos captados no cemitério.

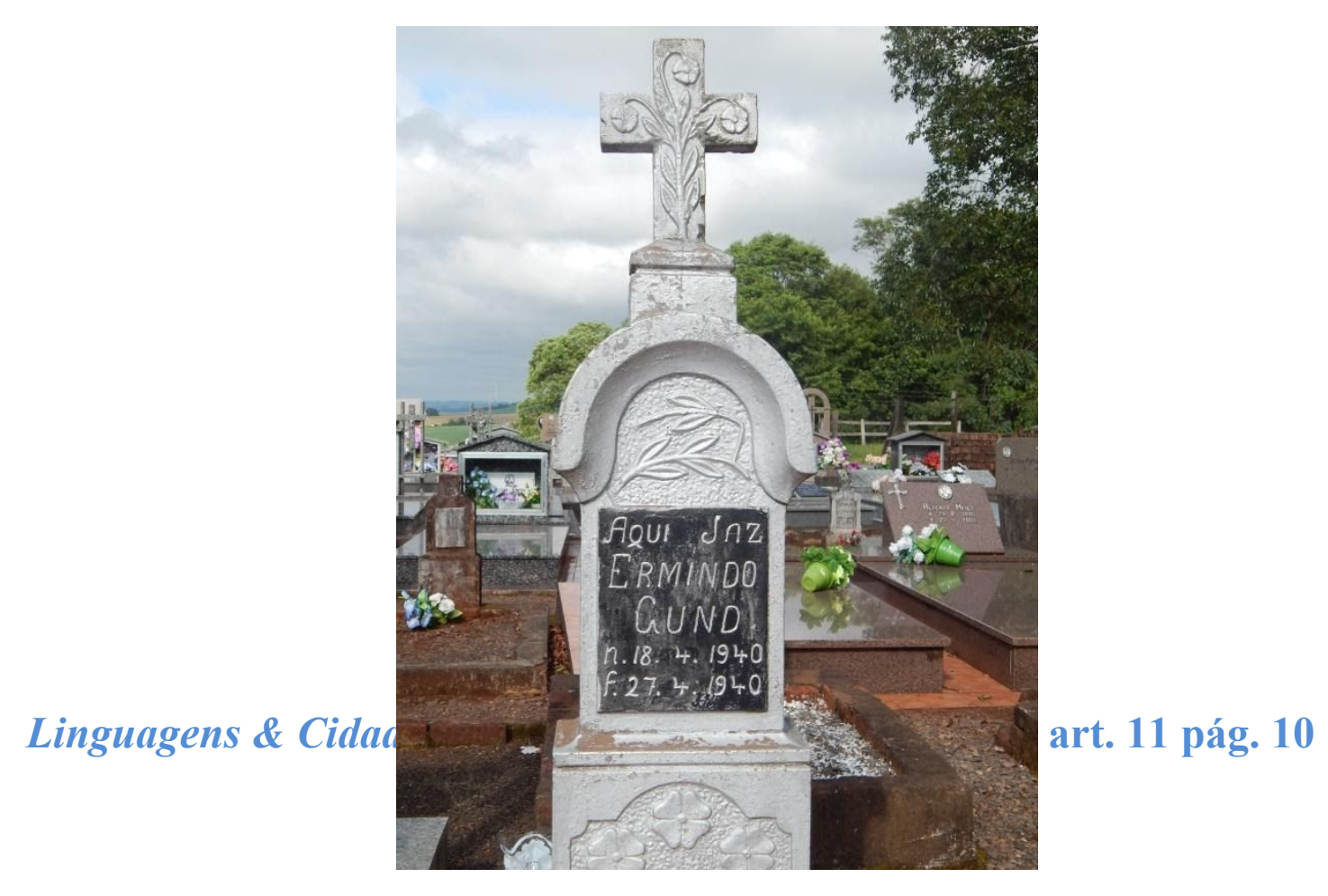




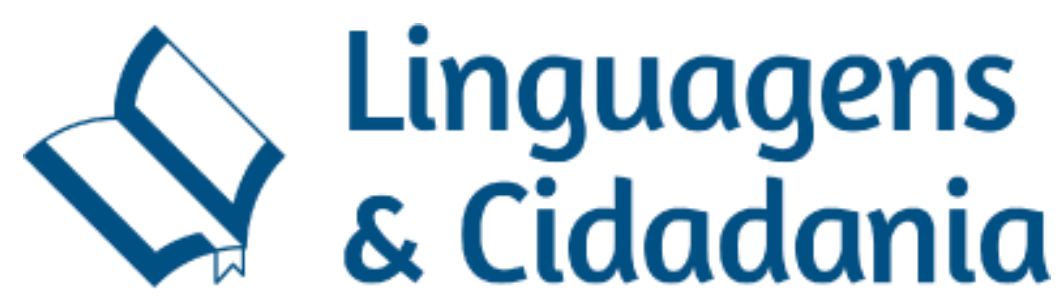

Figura 1: Lápide de 1940.

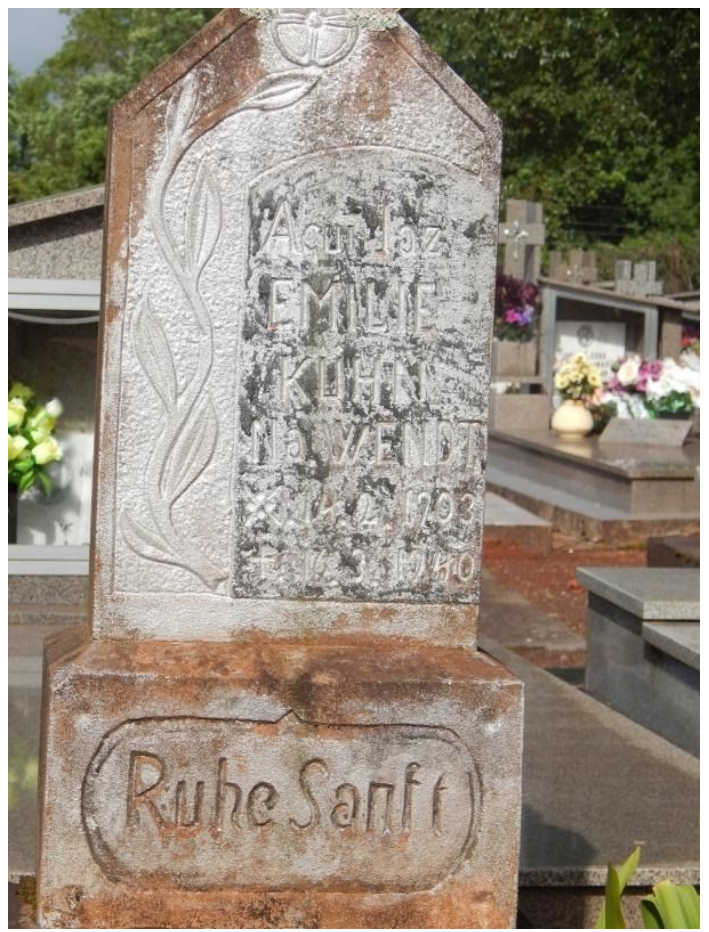

Enunciado em português.

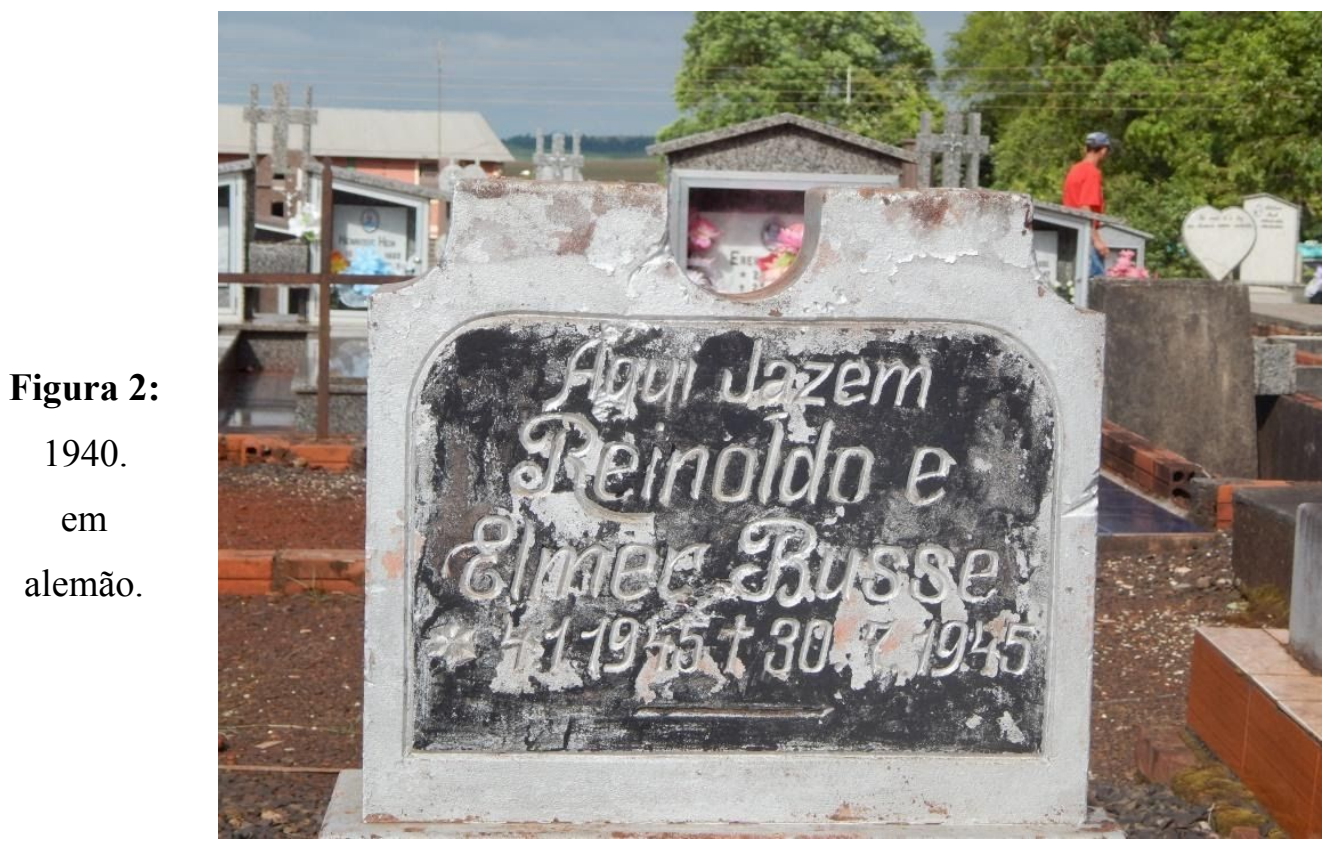

Lápide de

Enunciado

português e

Linguagens \& Cidadania, v. 21, n. esp., jan./dez. 2019 - art. 11 pág. 11 


\section{$\checkmark$ Linguagens \& Cidadania}

Figura 3: Lápide de 1945. Enunciado em português.

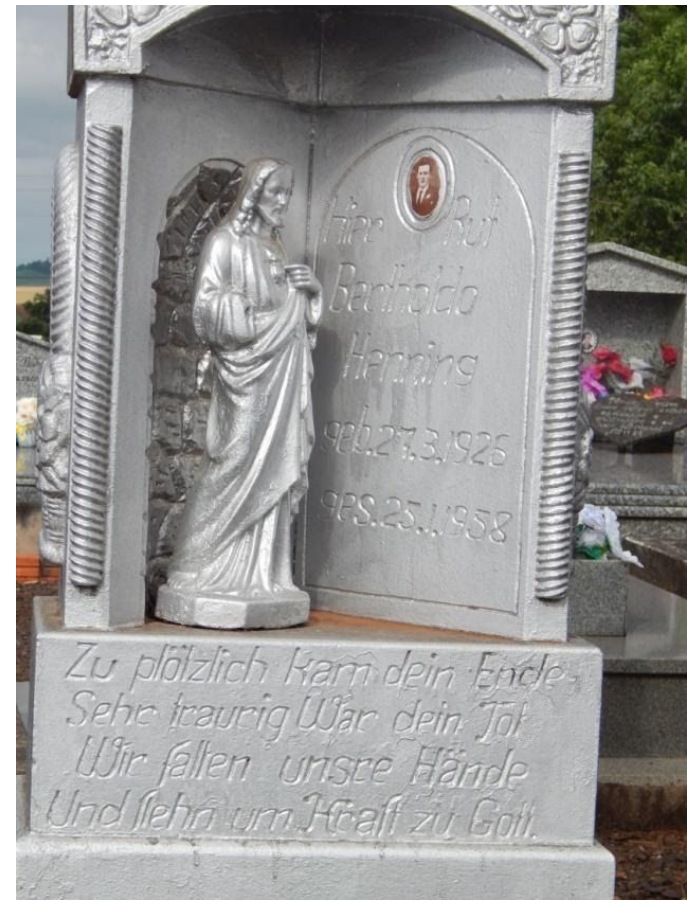

Figura 4: Lápide de 1958. Enunciado em alemão.

Entre 1937 a 1945 os enunciados são escritos em português. Com raras exceções, em português e alemão. Nesse período, estava em vigor a Política de Nacionalização de Getúlio Vargas, que tinha por objetivo interditar as línguas de imigração, pois se apresentavam como um perigo para a integridade da identidade nacional. 
enunciados

\section{Linguagens

Após

voltam a ser todos escritos em alemão, língua materna dos sujeitos imigrantes e seus descendentes, pois, nesse período, a região já não estava sob os efeitos tão intensos da política de nacionalização. Apesar da memória, das marcas da interdição, a língua alemã volta a ser inscrita nas lápides, significando politicamente os sujeitos em seu espaço derradeiro.

Conforme estudo anterior (FIEPKE, WEBER e ZORTÉA, 2016), percebemos que a perseguição linguística foi intensa no município de Novo Machado - RS e região. Refletiu na vida religiosa, social, escolar, e como podemos observar agora, por meio deste movimento inicial de pesquisa, também deixou as suas marcas nas últimas palavras materializadas na trajetória dos sujeitos no mundo.

\section{ALGUMAS CONSIDERAÇÕES}

A partir de um movimento de pesquisa inicial, mobilizamos alguns conceitos teóricos imprescindíveis para o desenvolvimento do estudo, bem como, traçamos, ainda que passível de alterações, os primeiros procedimentos metodológicos. É relevante a reflexão acerca dos Espaços de Enunciação (GUIMARÃES, 2002), Memória da Língua, Políticas Linguísticas.

Em uma busca inicial por espaços públicos de enunciação da língua de imigração alemã, deparamo-nos com inscrições em lápides do cemitério municipal. Por meio da perspectiva analítica, observa-se que o silêncio se manifesta duplamente nos enunciados de sujeitos que já foram calados pela morte, e como se não bastasse, calados também pelo Estado, por meio da Política Linguística de Getúlio Vargas. Percebemos como a língua alemã se mantém presente e eternizada como língua de uma comunidade linguística de imigração, pela permanência da palavra escrita.

O silêncio se atravessa quando a língua materna dos sujeitos se cala e a língua portuguesa, imposta pelo Estado, passa a significar nas últimas palavras dos sujeitos. Assim, as lápides significam na história, a memória de sujeitos tomados pela língua de imigração, produzindo sentidos, ora silenciados, quando o Estado se revela ameaçador, ora resistentes mediante o conflito imposto nos espaços de enunciação. 
Hoje,

se consolidam

\section{Linguagens \\ \& Cidadania ase undes \\ como}

patrimônio linguístico e cultural da região, trazendo o registro de uma língua que signifícou, e ainda significa, para o seu povo. E ali, inscrita na pedra, resiste ao tempo, aos homens, e exala sentidos que transcendem as leis que o Estado impõe. O que foi silenciado em vida, resiste na morte, na lápide, na pedra que permanece.

\section{REFERÊNCIAS}

BALDIN, N.; MUNHOZ, E.M.B. Snowball (Bola de Neve): uma técnica metodológica para pesquisa em educação ambiental comunitária. X Congresso Nacional de Educação EDUCRE/I Seminário Internacional de Representações Sociais, Subjetividade e Educação SIRSSE. Curitiba, PR, $7^{\mathrm{a}} 10$ de novembro, 2011. Anais..., p.329-41

BENVENISTE, E. Problemas de Linguística Geral II. Campinas: Pontes, 2006.

BOLOGNINI, Carmen Zink; PAYER, Maria Onice. Línguas de imigrantes. Cienc. Cult. vol.57 n.2. São Paulo, 2005. Disponível em:

http://cienciaecultura.bvs.br/scielo.php?pid=S000967252005000200020\&script=sci_arttext Acesso em: 14 out. 2017

BRUST, Viviane. O efeito "Chapéu de Clementis": Imagens do sujeito imigrante italiano na Quarta Colônia. 2013. 174 p. Dissertação de Mestrado - Universidade Federal de Santa Maria, Santa Maria, 2013.

CAMPOS, Cynthia Machado. A política da língua na era Vargas. Campinas, SP: Editora da Unicamp, 2006.

GUIMARÃES, Eduardo. Enunciação, Língua, Memória. Revista da ANPOLL, n², p.27-33, 1996.

Os limites do sentido. Campinas: Pontes, 2002.

Semântica: enunciação e sentido. Campinas, SP: Pontes Editores, 2018.

MARIANI, B. Colonização Lingüística. Campinas: Pontes, 2004.

ORLANDI, Eni P. Análise de Discurso: princípios e procedimentos. $4^{\mathrm{a}}$ ed. Campinas: Pontes, 2002. 


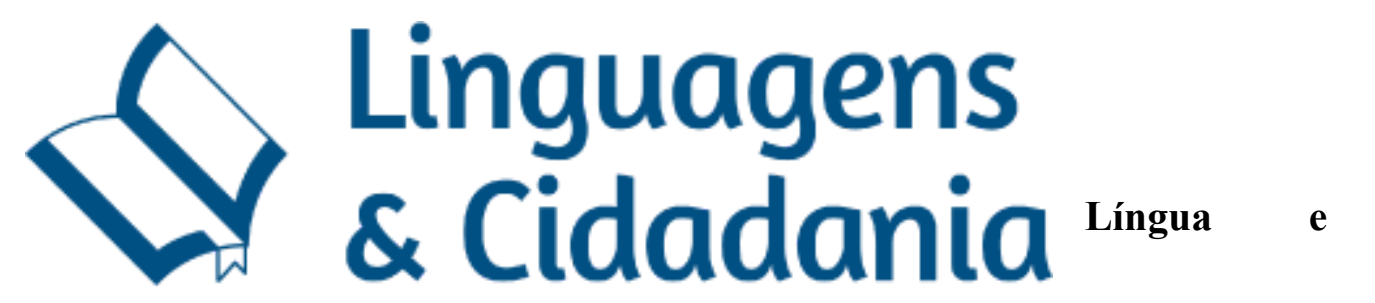

conhecimento linguístico: para uma história das ideias linguísticas no Brasil. 2.ed. São Paulo: Cortez, 2013.

PAYER, Maria Onice. Memória da língua: imigração e nacionalidade. São Paulo: Escuta, 2006.

PARCIANELLO, Juciane Ferigolo. O dizer na e sobre a língua de sujeitos descendentes de imigrantes italianos e a fronteira enunciativa. 2011. $115 \mathrm{f}$. Dissertação (Mestrado em Letras). Universidade Federal de Santa Maria, Santa Maria, 2013. Disponível em: http://cascavel.ufsm.br/tede//tde_busca/arquivo.php?codArquivo=3596. Acesso em: 25 ago. 2015.

PRIEBE, Gretel; SCHROEDER, Nedi. Novo Machado conta a sua História. 2 ed. Novo Machado: 2005.

TATSCH, L. Estudo enunciativo da designação da expressão Línguajar gaúcho na obra de Dante de Laytano: Reflexão sobre a noção de acontecimento. Web Revista Sociodialeto, 2013. Disponível em:

http://sociodialeto.com.br/edicoes/16/10012014013808.pdf. Acesso em: 20/05/2018.

WEBER, Andrea. Política de línguas e mídia no mercosul: um estudo enunciativo de jornais de fronteira. Tese (Doutorado em Letras) - Universidade Federal de Santa Maria, Santa Maria, RS, 2013. 